\title{
PERANCANGAN APLIKASI BUS FTI UKSW MENGGUNAKAN BARCODE BERBASIS ANDROID
}

\author{
Daniel Ritchie Indriyanto Supatra ${ }^{1}$, Radius Tanone ${ }^{2}$ \\ 1,2 Fakultas Teknologi Informasi, Universitas Kristen Satya Wacana
}

Article Info:

Dikirim: 05 September 2019

Direvisi: 17 Oktober 2019

Diterima: 17 Oktober 2019

Tersedia Online: 31 Desember 2019

Penulis Korespondensi:

Daniel Ritchie Indriyanto Supatra

Fakultas Teknologi Informasi,

Universitas Kristen Satya Wacana,

Salatiga, Indonesia

Email: danielritchie100@gmail.com

\begin{abstract}
Abstrak: FTI UKSW memiliki bus untuk mengantar mahasiswa dari kampus utama yang berada di jalan Diponegoro ke kampus FTI UKSW yang berada di jalan Gunung Payung. Banyak mahasiswa yang menggunakan bus FTI UKSW tersebut untuk berangkat ke kampus FTI UKSW. Tetapi masalahnya adalah belum tersedia aplikasi bus FTI UKSW. Perancangan aplikasi bus FTI UKSW ini dibuat untuk menjawab permasalahan tersebut, agar nantinya dapat membantu mahasiswa untuk mendapatkan informasi tentang jadwal, serta informasi pengumuman terbaru lainnya seputar bus FTI UKSW. Aplikasi bus FTI UKSW ini juga dapat membantu pihak universitas untuk mendata mahasiswa yang menggunakan bus FTI UKSW tersebut. Cara mendata mahasiswa yang menggunakan bus FTI UKSW adalah dari hasil data yang didapatkan dari mahasiswa atau penumpang bus yang sudah melakukan scan barcode saat akan naik atau menggunakan bus FTI UKSW. Karena itu perancangan aplikasi bus FTI UKSW ini menggunakan teknologi barcode (pada aplikasi ini menggunakan QR Code) dan berbasis android. Aplikasi ini juga menggunakan Firebase Realtime Database yang berfungsi sebagai database yang bisa mendapatkan data secara realtime atau waktu pada saat itu juga. Hasil pada penelitian ini adalah telah berhasil merancang aplikasi bus FTI UKSW menggunakan barcode berbasis android, sehingga aplikasi ini dapat membantu mahasiswa atau penumpang bus dan pihak universitas yang dimana sebelumnya tidak ada aplikasi bus FTI UKSW.
\end{abstract}

Kata kunci: firebase realtime database; qr code; android; bus FTI UKSW.

\begin{abstract}
The SWCU FTI has a bus to take students from the main campus that is on the Diponegoro street to the SWCU FTI campus which is on the Gunung Payung street. Many students use the SWCU FTI bus to go to the SWCU FTI campus. However, the problem is that there is no SWCU FTI bus application. The design of the SWCU FTI bus application was made to answer these questions, in order to help students get information about schedules, as well as the latest information related to the SWCU FTI bus. The SWCU FTI bus application can also help the university to register students who use the SWCU FTI bus. The way to record students who use the SWCU FTI bus is from the data obtained from students or bus passengers who have already scanned the barcode when they are going to ride or use the SWCU FTI bus. Because of that the SWCU FTI bus application design uses barcode technology (in this application it uses a QR Code) and this application is based on android. This application also uses the Firebase Realtime Database which functions as a database that can get realtime or time data at a moment's notice. The results of this study are successful applications made by the SWCU FTI that use android-based barcodes, so that this application can help students or bus passengers and universities that previously did not have the SWCU FTI bus application.
\end{abstract}

Keywords: firebase realtime database; qr code; android; SWCU FTI Bus. 


\section{PENDAHULUAN}

Pada tahun 2016 gedung Fakultas Teknologi Informasi Universitas (FTI) Kristen Satya Wacana (UKSW) Salatiga berpindah lokasi dari Jalan Diponegoro 52-60 Salatiga ke Jalan Gunung Payung, Kel. Blotongan, Kec. Sidorejo, Salatiga. Gedung FTI UKSW Salatiga tepatnya terletak di atas bukit, sehingga letaknya lumayan jauh dari jalan raya dan menyebabkan mahasiswa cukup kesulitan untuk ke sana, apalagi jika mahasiswa tersebut kos di dekat lokasi gedung UKSW utama yang di jalan Diponegoro [1]. Karena itu dari pihak FTI UKSW telah menyediakan bus yang awal penjemputannya dari gedung UKSW utama yaitu di jalan Diponegoro ke arah FTI UKSW dan juga sebaliknya. Jadwal beroperasi bus FTI UKSW setiap hari Senin sampai Jumat selama, dari jam 06.30 yang awalnya dari gedung UKSW Diponegoro sampai jam 18.00 dari gedung FTI UKSW Blotongan [2].

Selama ini bus FTI UKSW boleh digunakan oleh semua mahasiswa UKSW termasuk mahasiswa dari luar FTI UKSW atau dari fakultas lainnya yang ingin pergi ke gedung FTI UKSW Blotongan tersebut [3]. Pada saat ini pun bus FTI UKSW masih beroperasi dengan jumlah penumpang yang tidak tentu di setiap jam dan harinya, karena masih belum ada aplikasi untuk membantu memberikan informasi tentang jumlah penumpang yang menggunakan bus tersebut [4]. Dan juga, apakah semua penumpang bus tersebut adalah mahasiswa FTI UKSW semua atau mungkin bisa juga dari luar FTI UKSW seperti misalnya dari FSM (Fakultas Science Mathematic), FBS ( Fakultas Bahasa dan Seni) ataupun dari fakultas lainnya. Dan selama ini tidak pernah tahu, berapakah jumlah tepatnya penumpang yang menggunakan bus FTI UKSW pada hari apa dan jam berapa [5].

Berdasarkan latar belakang masalah tersebut, maka rumusan masalah pada penelitian ini adalah bagaimana perancangan aplikasi bus FTI UKSW menggunakan barcode berbasis android. Sehingga nantinya diharapkan dari perancangan aplikasi ini adalah dapat membantu memberikan informasi seputar bus kepada mahasiswa atau penumpang bus yang menggunakan bus FTI UKSW tersebut. Selain itu juga diharapkan dapat membantu pihak FTI UKSW untuk mendapatkan informasi tentang penumpang bus FTI UKSW tersebut seperti informasi penumpang secara umum seperti nama, jenis kelamin, email, fakultas, dan jurusannya apa. Selain informasi penumpang bus secara umum, ada juga informasi lainnya seperti informasi hari dan jam berapakah penumpang tersebut menggunakan bus, informasi jadwal hari dan jam beroperasinya bus FTI UKSW. Nantinya diharapkan, setiap penumpang yang akan naik bus FTI UKSW harus melakukan scan barcode yang telah disediakan dengan menggunakan aplikasi bus FTI UKSW tadi, sehingga dari scan barcode tersebut menghasilkan informasi informasi tersebut.

\section{TINJAUAN PUSTAKA}

Langkah-langkah penelitian dituliskan dalam bentuk narasi: (1), (2), Heading diberi nomor menggunakan angka $\operatorname{arab}(1,2,3$, dst). Jika heading anda melebihi satu, gunakan level kedua heading seperti di bawah ini. Heading ditulis dalam huruf kapital semua. Penulisan antar bab, sub bab dan isi diberi jarak 1 spasi.

\subsection{Penelitian Terdahulu}

Ada beberapa penelitian terdahulu yang mendukung untuk penelitian ini, diantaranya yaitu penelitian yang berjudul "Pemanfaatan $Q R$ Code Scanner Untuk Aplikasi Penampil Data Koleksi Pamer Di Museum Negeri Sonobudoyo Berbasis Android". Pemanfaatan $Q R$ code scanner tersebut dapat digunakan unuk menampilkan informasi benda koleksi museum dari scan $Q R$ code tersebut. Adapun pembuatan aplikasi $Q R$ code scanner tersebut menggunakan ZBar Library [6]. Kemudian penelitian yang lainnya berjudul Aplikasi Info Halal Menggunakan Barcode Scanner Untuk Smartphone Android, membahas tentang informasi kehalalan makanan atau suatu barang dengan melakukan scan barcode menggunakan aplikasi tersebut dan nantinya pengguna dapat melihat hasil nomor sertifikat halal resmi yang telah terdaftar secara langsung dari smartphone tersebut [7].

Pada penelitian berjudul "E-Tiket Bus Trans Batam Dengan Menggunakan $Q R$ - Code System Berbasis Android", membahas tentang penyandian kode tiket yang dijadikan sebagai e-tiket yang tidak perlu menggunakan kertas, melainkan dipindai menggunakan smartphone dari barcode yang sudah tertera. Adapun aplikasi tersebut dirancang dengan menggunakan Java Android dan PHP [8]. Pada penelitian berjudul Sistem Informasi Penjualan Berbasis Android Dengan Memanfaatkan QR-Code Dan Barcode. Nantinya aplikasi android tersebut dapat memberikan informasi penjualan hanya dengan scan $Q R$ atau barcode dan hasilnya dapat dilihat di smartphone pengguna, sehingga lebih murah dengan menggunakan smartphone yang dulunya dari komputer dan lebih fleksibel [9].

Dan pada penelitian terdahulu yang mendukung penelitian ini adalah penelitian yang berjudul "Perancangan Aplikasi Sistem Informasi Medis Menggunakan Barcode Berbasis Desktop Dan Android". Aplikasi ini dibuat untuk membantu dokter mendapatkan informasi data pasien melalui scan barcode yang ditampilkan pada aplikasi desktop ataupun android, dan juga dapat untuk memperbarui informasi data pasien. Aplikasi tersebut dirancang dengan visual basic, bahasa pemrograman Java dan MySQL untuk sistem database [10]. Berdasarkan hasil yang didapat pada penelitian sebelumnya, bahwa dengan menggunakan fitur scan barcode akan lebih mempermudah untuk mengidentifikasikan suatu hal yang berisi beberapa informasi yang didapatkan dengan cukup mudah, yaitu dengan cara scan barcode[11]. 
Pada penelitian disini akan sedikit berbeda dengan penelitian yang sebelumnya. Karena pada penelitian disini menggunakan $Q R$ Code dan firebase realtime database. Pengertian $Q R$ Code sendiri adalah berisi kode matriks berjenis dua dimensi yang didapat dari hasil perkembangan kode matriks sebelumnya, yaitu kode matriks berjenis satu dimensi. $Q R$ Code ini dapat digunakan untuk menyimpan data dengan kapasitas yang cukup besar. Kelebihannya menggunakan $Q R$ Code adalah lebih murah dalam penggunaannya, karena dalam pembuatan $Q R$ Code telah tersedia yang gratis dan juga dalam penggunaannya tidak memerlukan perangkat khusus untuk melakukan scan, karena juga sudah tersedia $Q R$ Code scanner secara gratis. Kelebihan lain dari menggunakan $Q R$ Code yaitu sistem dapat cepat memberikan respon terkait hasil scan tersebut. Sehingga di dalam penelitian ini akan menggunakan $Q R$ Code yang diharapkan dapat memberikan hasil yang efektif dan efisien[12]. Gambar contoh $Q R$ Code dapat dilihat pada gambar 1.

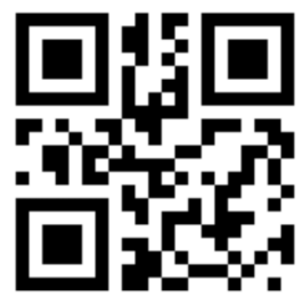

\section{Gambar 1. Contoh QR Code [12].}

Sedangkan firebase realtime database sendiri adalah database yang disediakan oleh firebase yang dimana tidak memerlukan database seperti pada umumnya, contohnya yaitu seperti MySQL. Kelebihan menggunakan firebase realtime database ini adalah ketika terjadi perubahan data didalam database tersebut, maka pengguna juga akan segera mendapatkan update data terbaru tersebut pada waktu itu juga atau dapat disebut secara realtime. Di dalam penelitian ini akan menggunakan firebase realtime database yang dimana nantinya setiap ada perubahan pada data, maka pengguna dan admin pada aplikasi bus FTI UKSW ini akan selalu mendapatkan informasi perubahaan tersebut juga secara realtime[13].

\section{METODOLOGI PENELITIAN}

Metode penelitian yang akan digunakan dalam penelitian ini adalah menggunakan metode penelitian R\&D (Research and Development). Tahapan penelitian yang dilakukan dalam perancangan aplikasi bus FTI UKSW menggunakan barcode berbasis android, dapat dilihat pada Gambar 2.

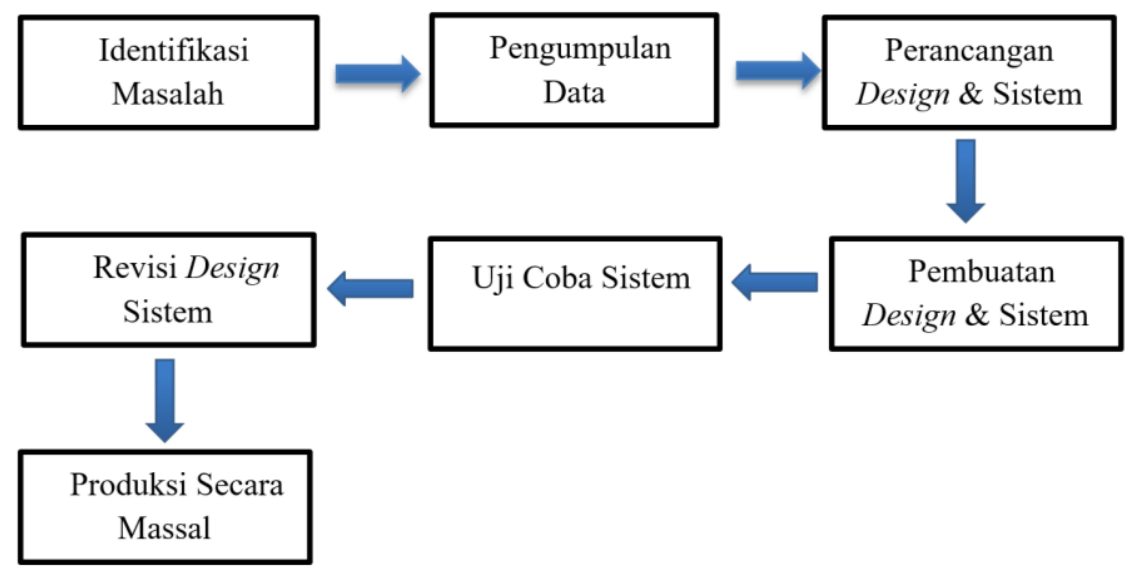

Gambar 2. Tahapan Metode R \& D

(Sumber : Konsep Penelitian R\&D Dalam Bidang Pendidikan)

Tahapan penelitian pada Gambar 2 dijelaskan sebagai berikut : 1) Tahapan pertama yaitu Tahap identifikasi masalah. Pada tahap ini dilakukan identifikasi terhadap permasalahan yang ada. Hasil identifikasi masalah yang dilakukan disini adalah bahwa belum adanya aplikasi bus FTI UKSW. 2) Tahapan kedua adalah tahap pengumpulan data. Setelah identifikasi masalah sudah dilakukan, maka selanjutnya diperlukan untuk melakukan pengumpulan data atau informasi yang penting untuk menjawab permasalahan tersebut. Pada tahap ini dilakukan pengumpulan data terkait aplikasi bus FTI UKSW menggunakan barcode berbasis android yaitu informasi seputar mahasiswa, dan informasi bus FTI UKSW. Secara mendalam, contoh kumpulan data tersebut seperti data mahasiswa FTI UKSW, data jadwal jam kerja beroperasinya bus FTI UKSW, dan lain-lain. 3) Tahapan ketiga adalah tahap perancangan design \& sistem. Pada tahap ini dilakukan perancangan sistem dengan menggunakan UML (Unified Modelling Language) untuk membuat alur program dari aplikasi bus FTI UKSW berbasis android 
ini yang akan dibangun. UML tersebut terdiri dari use case diagram, activity diagram, class diagram. Selain UML, perancangan sistem lainnya juga menggunakan teknologi barcode atau secara spesifik menggunakan $Q R$ code. 4) Tahapan keempat adalah pembuatan design \& sistem. Setelah dilakukan perancangan design \& sistem, maka selanjutnya akan dilakukan pembuatan design \& sistem tersebut. Di tahapan ini dilakukan pengerjaan dalam men-design aplikasi dan pembuatan sistem, termasuk pembuatan program atau aplikasi, sesuai dengan UML yang telah dibuat sebelumnya tersebut. Disini untuk pembuatan design dan sistem menggunakan Android Studio, firebase database realtime dan disupport oleh teknologi barcode scanner. 5) Tahapan kelima adalah uji coba sistem. Pada tahap ini dilakukan pengujian sistem oleh peneliti, dan jika masih dirasa kurang maka dapat menggunakan angket sebagai pengumpulan data untuk dapat lebih mengetahui lagi kelemahan dan kelebihan pada sistem tersebut. 6) Tahapan keenam adalah revisi design \& sistem. Setelah selesai dilakukan proses uji coba pada sistem aplikasi bus FTI UKSW dan jika ternyata masih ditemukan kekurangan dari sistem aplikasi tersebut, maka pada tahap ini akan dilakukan revisi atau perbaikan pada design dan sistemnya agar lebih baik lagi. 7) Tahapan ketujuh adalah produksi sistem secara massal. Jika sebelumnya sudah selesai dilakukan revisi dan perbaikan pada design \& sistem aplikasi bus FTI UKSW, maka pada tahap ini akan dilakukan produksi secara masal yang artinya aplikasi tersebut sudah siap untuk digunakan oleh mahasiswa atau penumpang bus FTI UKSW.

Seperti yang sudah dijelaskan sebelumnya, pada tahap ketiga yaitu tahap perancangan design \& sistem, bahwa perancangan sistem aplikasi bus FTI UKSW yang dibuat ini menggunakan teknologi barcode atau $Q R$ code dan UML(Unified Modelling Language) yang terdiri dari use case diagram, activity diagram, class diagram. Teknologi $Q R$ code disini sangat berperan penting dalam perancangan sistem di aplikasi bus FTI UKSW. Flowchart mekanisme $Q R$ code dalam membaca dan mengirimkan data dalam perancangan bus FTI UKSW ini dapat dilihat pada gambar 3.

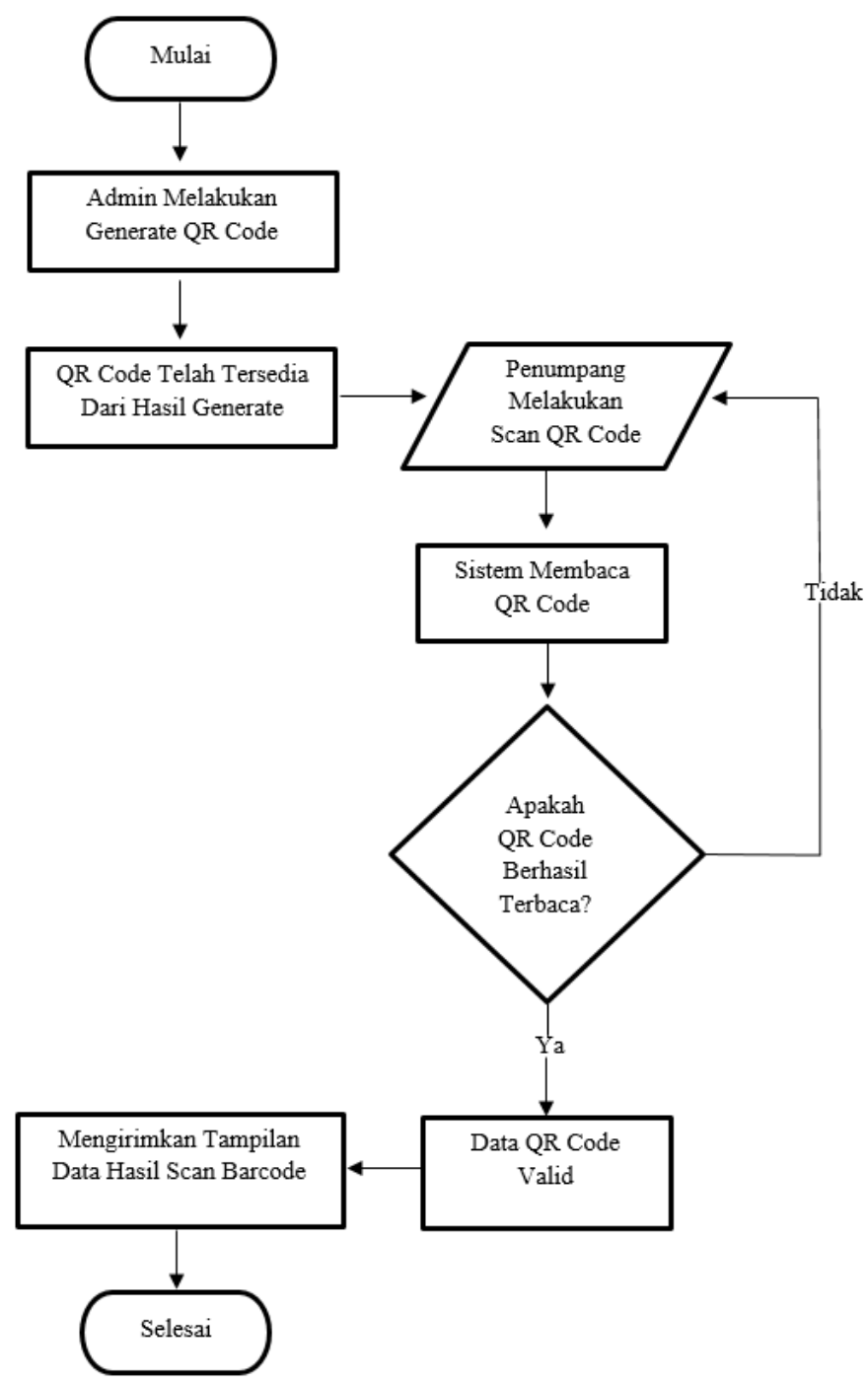

Gambar 3. Flowchart Mekanisme QR Code Pada Aplikasi BUS FTI UKSW 
Pada Gambar 3 dapat dijelaskan bahwa mekanisme $Q R$ Code dalam perancangan aplikasi ini dimulai dari admin yang sudah melakukan generate $Q R$ code terlebih dahulu, dan kemudian jika berhasil di generate maka akan terbentuk $Q R$ code terbaru yang nantinya digunakan oleh penumpang unuk di scan. Selanjutnya penumpang dapat melakukan scan pada $Q R$ code yang telah berhasil di generate tersebut. Setelah itu sistem akan membaca $Q R$ code yang di scan tadi. Jika berhasil terbaca QR code tersebut, maka sistem akan memproses ke tahap selanjutnya. Tetapi jika sistem tidak berhasil membaca scan $Q R$ code tersebut, maka harus melakukan scan ulang $Q R$ code lagi sampai sistem benar-benar berhasil membaca data $Q R$ code tersebut. Tahapan selanjutnya jika sistem berhasil membaca dan memproses data $Q R$ code tersebut, maka sistem akan mengirimkan tampilan data hasil scan $Q R$ code kepada penumpang.

Kemudian selain tekonologi $Q R$ code, ada juga use case diagram. Use case diagram adalah gambaran yang digunakan untuk menjelaskan interaksi yang terjadi antara aktor yang satu dengan aktor yang lain, dan juga menjelaskan interaksi antara aktor dengan fungsi-fungsi yang berada di dalam sistem tersebut. Disini terdapat dua aktor dalam sistem aplikasi bus FTI UKSW menggunakan barcode berbasis android, dua aktor tersebut yaitu admin dan penumpang bus atau mahasiswa. Berikut adalah use case diagram yang dapat dilihat pada gambar 4.

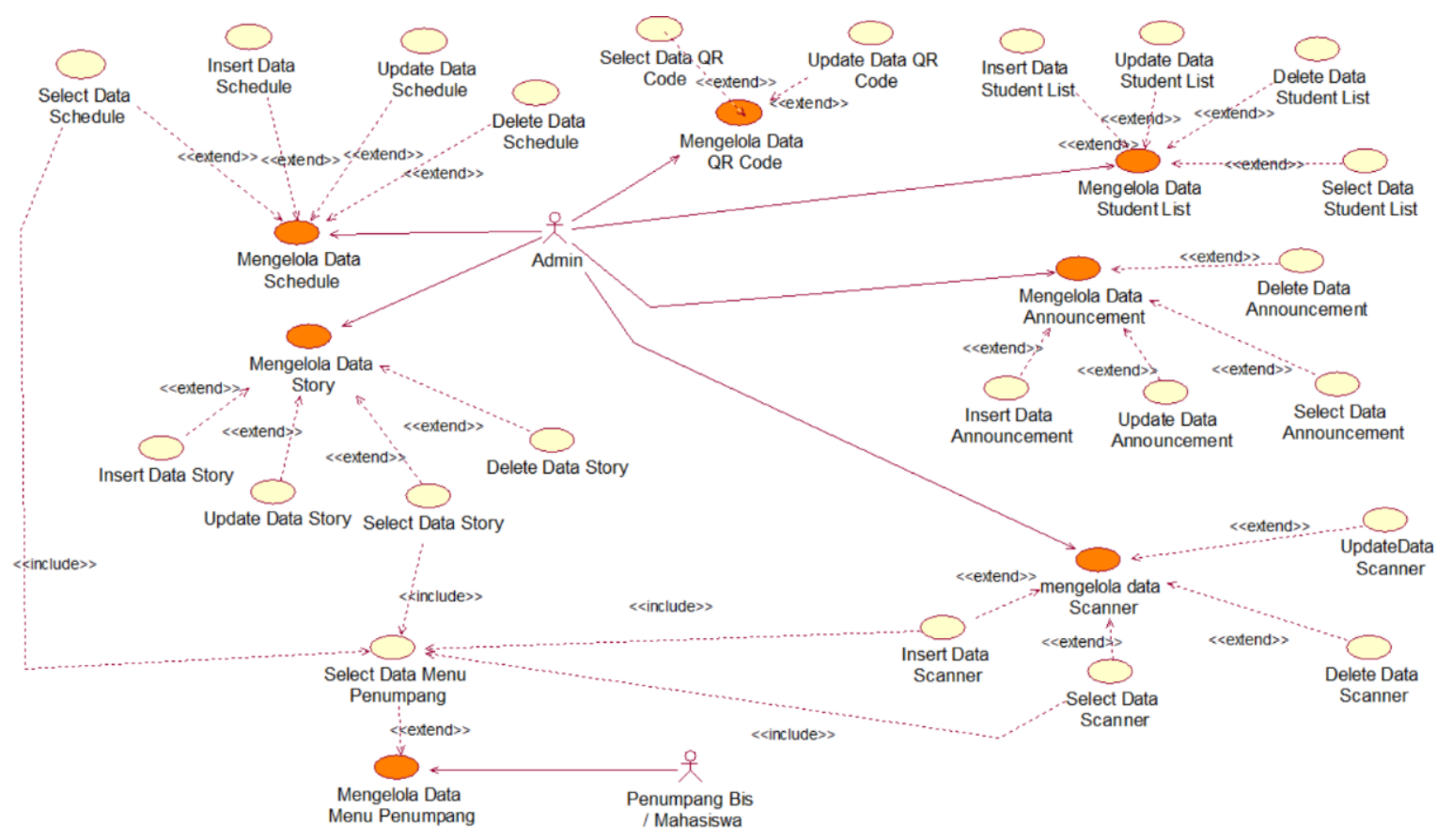

Gambar 4. Use Case Diagram Aplikasi Bus FTI UKSW

Pada gambar 4 dapat dijelaskan bahwa terdapat 2 aktor, yaitu admin dan penumpang bus. Peran admin sebagai aktor utama di dalam sistem yang dapat melakukan create, read, update, delete terhadap data yang ada di dalam sistem. Admin yang berperan untuk mengelola data mahasiswa, data bus, dan data informasi pada sistem aplikasi bus FTI UKSW tersebut. Sedangkan peran aktor penumpang bus dapat melihat data informasi yang sudah diolah oleh admin maupun yang telah disediakan oleh sistem dan penumpang bus juga dapat melakukan update data. Update data yang bisa dilakukan oleh penumpang bus yang dimaksud adalah dari hasil setelah dilakukan scan barcode yang kemudian diolah oleh sistem dan dapat dilihat oleh penumpang bus.

Selanjutnya adalaha activity diagram. Activiy diagram adalah gambaran tentang aktifitas-aktifitas yang terjadi di dalam sistem dari awal proses kerja sistem hingga akhir proses kerja sistem. Karena itu pada activity diagram dapat memperlihatkan langkah-langkah proses kerja sistem yang dilakukan oleh admin dan penumpang bus. Berikut gambar activity admin yang dapat dilihat pada gambar 5 dan activity penumpang pada gambar 6 . 


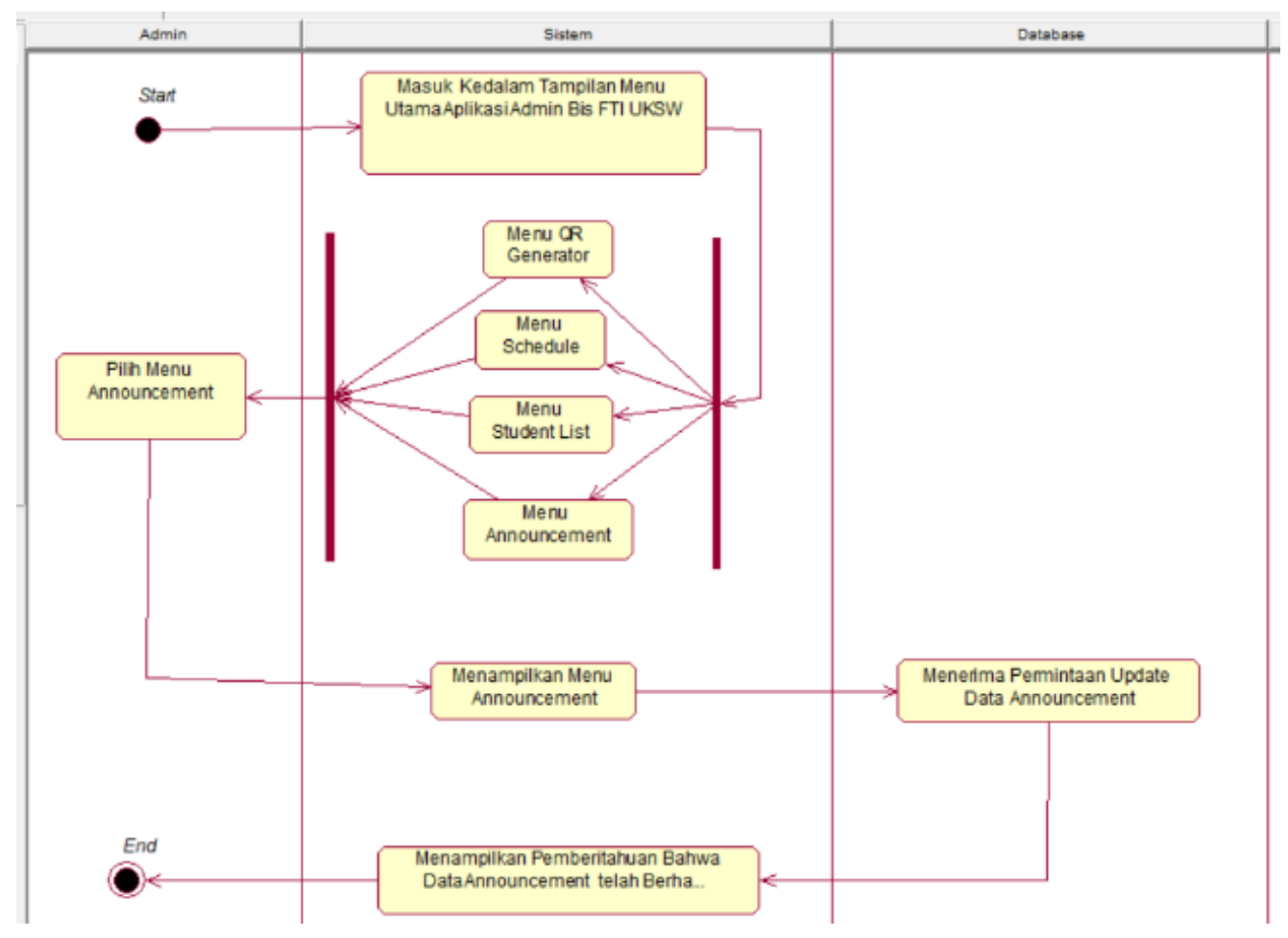

Gambar 5. Activity Diagram Aplikasi Bus FTI UKSW Pada Admin

Pada gambar 5 menggambarkan tentang aktifitas admin saat melakukan proses update pada menu announcement pada sistem aplikasi bus FTI UKSW. Langkah pertama Pertama, admin harus masuk kedalam aplikasi admin bus FTI UKSW. Fitur admin dan penumpang disini tidak berada di dalam satu aplikasi yang sama, melainkan dipisah menjadi dua aplikasi. Dua aplikasi tersebut yaitu admin bus FTI UKSW dan aplikasi penumpang bus FTI UKSW. Karena fitur admin dan penumpang bus FTI UKSW tidak berada di dalam satu aplikasi, maka admin bus FTI UKSW bisa langsung masuk ke dalam aplikasi tanpa melalui proses menu login dahulu. Kemudian akan muncul tampilan awal pada aplikasi admin yaitu menu QR generator, menu schedule, menu student list, dan menu announcement. Selanjutnya admin memilih menu announcement untuk melakukan update announcement. Setelah admin selesai melakukan update announcement, maka sistem akan mengirimkan permintaan update ke database, yang kemudian dari database akan menerima permintaan update data announcement tersebut dan kemudian akan dikirimkan kembali ke sistem bahwa data announcement tersebut telah berhasil di update oleh admin yang nantinya update announcement tersebut dapat dilihat oleh admin ataupun penumpang bus tersebut. 


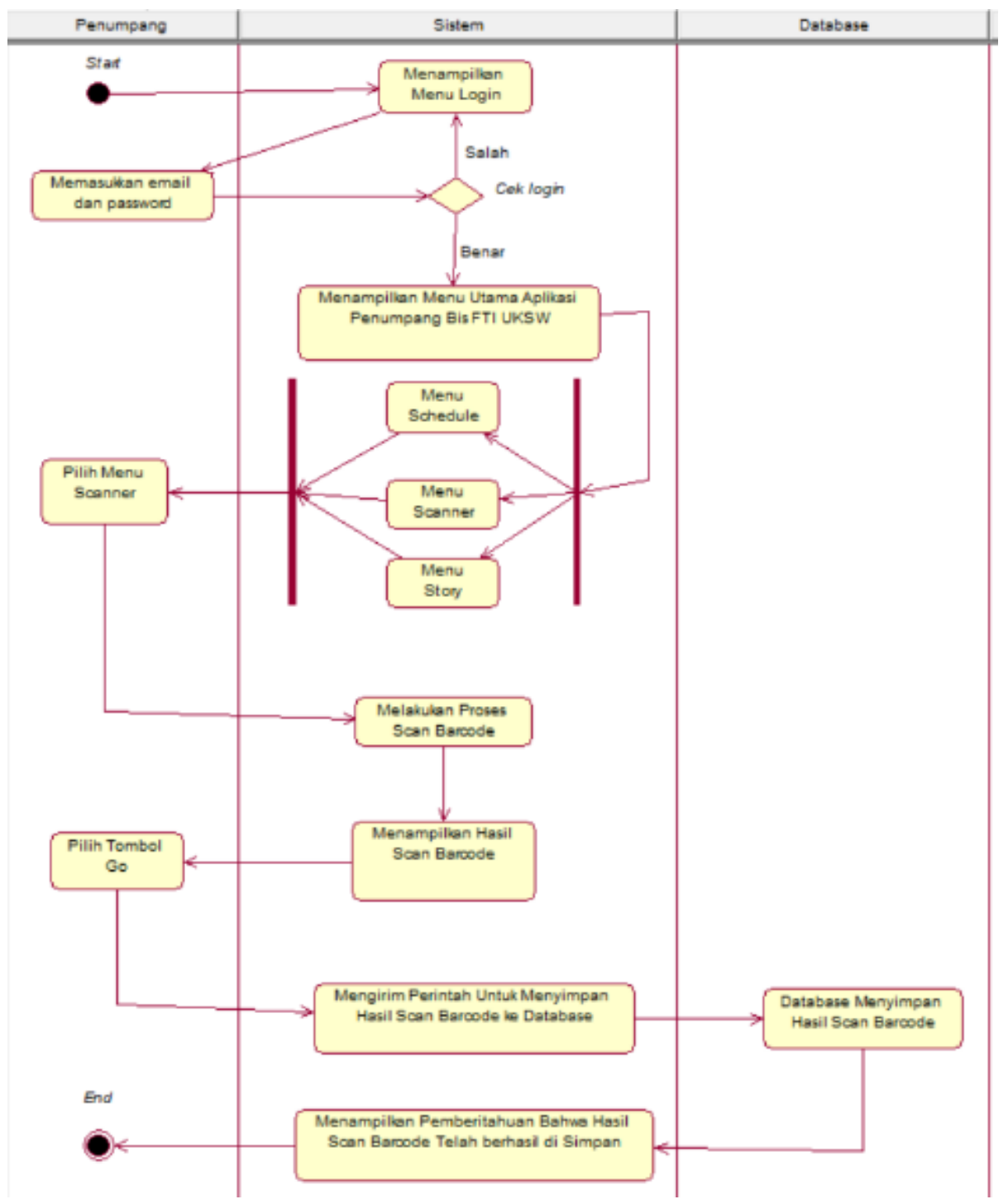

\section{Gambar 6. Activity Diagram Penumpang Aplikasi Bus FTI UKSW Pada Penumpang}

Pada gambar 6 menunjukkan aktivitas penumpang bus saat melakukan proses scan barcode. Sebelumnya, admin telah melakukan input data mahasiswa FTI UKSW yang artinya jika data tersebut telah ada di dalam sistem, maka admin dapat melakukan update data yang sudah ada didalam sistem tersebut. Kemudian jika sudah terdaftar pada sistem, maka mahasiswa ataupun penumpang bus dapat melakukan login terlebih dahulu pada aplikasi penumpang bus FTI UKSW. Jika login gagal maka akan secara otomatis keluar dari aplikasi tersebut dan harus masuk kembali ke aplikasi penumpang bus FTI UKSW dan harus melakukan login kembali hingga benar - benar login tersebut benar atau diterima. Tetapi, jika sudah berhasil login maka pengguna akan dibawa masuk ke tampilan menu utama pada aplikasi penumpang bus FTI UKSW. Pada tampilan menu tersebut terdapat 3 menu utama, yaitu menu schedule, menu scanner, menu story.

Setelah itu penumpang harus memilih menu scanner untuk melakukan scan barcode, dan selanjutnya sistem akan melakukan proses scan barcode. Jika scan barcode tersebut berhasil maka akan muncul tampilan bahwa penumpang tersebut sesuai dengan saat waktu dilakukan proses scan barcode akan ditampilkan. Kemudian penumpang harus memilih tombol go untuk mengirimkan hasil dari proses scanner tersebut ke sistem dan selanjutnya dari sistem akan mengirimkan perintah kepada database untuk menyimpan hasil scanner tersebut. Setelah berhasil menyimpan hasil scan pada database, maka akan dilempar kembali ke sistem berupa pengiriman pemberitahuan ke penumpang bahwa proses scan barcode telah berhasil, dan penumpang akan mendapatkan pemberitahuan tersebut.

Terakhir adalah class diagram. Class diagram adalah penggambaran struktur sistem yang dilihat dari segi setiap kelasnya, yang tentunya setiap kelas-kelas tersebut sangat dibutuhkan dalam membangun suatu sistem tersebut. Setiap kelas yang dimaksud itu diantaranya adalah name, attribute, operation. Ada 3 paket yang terbentuk pada class diagram ini, yaitu boundary, controller, dan entity. Class diagram sistem aplikasi bus FTI UKSW dapat dilihat pada gambar 7. 


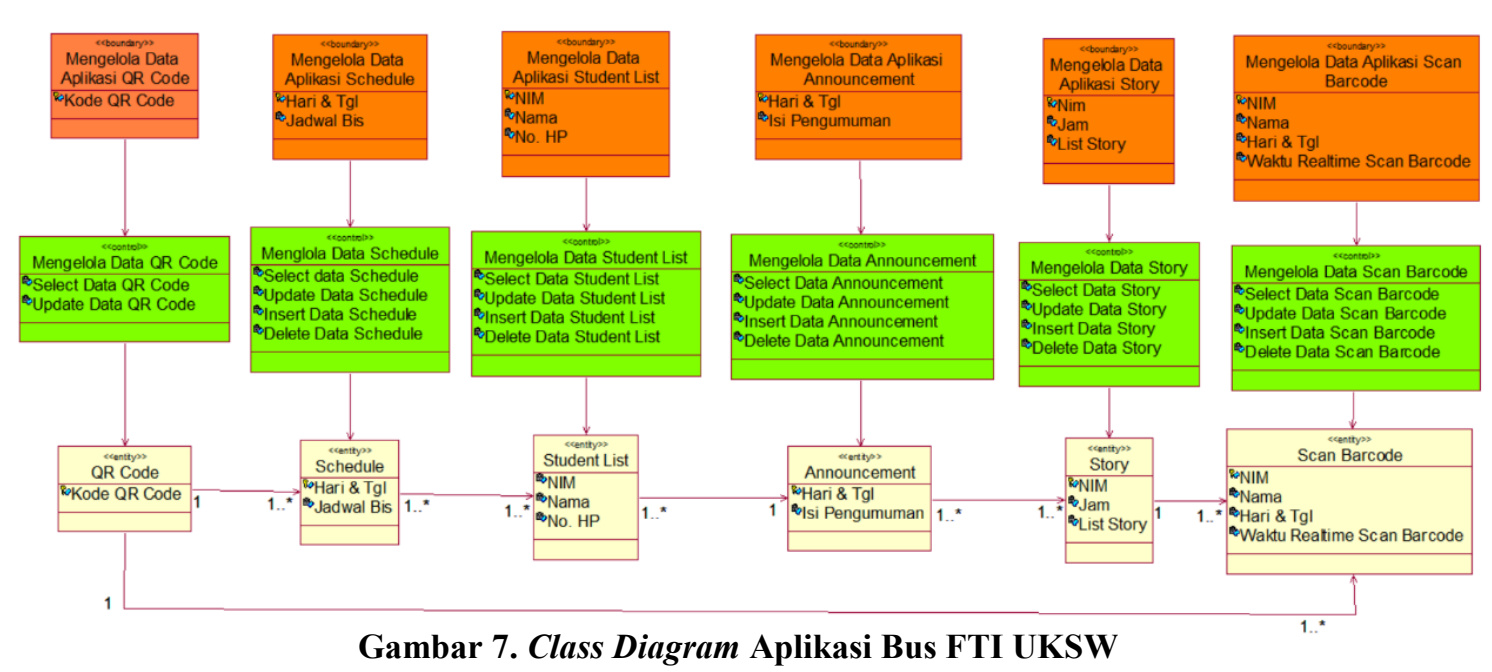

Gambar 7 adalah gambaran dari beberapa class yang ada di dalam sistem aplikasi bus FTI UKSW. Kelas yang pertama adalah kelas boundary, kelas boundary tersebut diantaranya adalah data aplikasi QR Code, data aplikasi schedule, data aplikasi student list, data aplikasi announcement, data aplikasi story, data aplikasi scan barcode. Kelas boundary ini yang akan menjadi interface dari tampilan aplikasi tersebut. Kedua adalah kelas control, kelas control ini berisi perintah atau fungsi yang nantinya digunakan untuk mengelola data dari entity agar dapat ditampilkan kepada pengguna atau user. Kelas control tersebut adalah data QR Code, data schedule, data student list, data announcement, data story, data scan barcode. Kelas ketiga adalah kelas entity, kelas entity tersebut memiliki fungsi sebagai jembatan untuk berkomunikasinya antara sistem dengan database. Kelas Entity tersebut adalah QR Code, schedule, student list, announcement, story, scan barcode.

\section{HASIL DAN PEMBAHASAN}

Fitur admin dan penumpang tidak berada dalam satu aplikasi, maka tentu saja tampilan aplikasi pada admin berbeda dengan tampilan aplikasi pada penumpang bus FTI UKSW. Sehingga dirancanglah menjadi 2 aplikasi yaitu, aplikasi admin bus FTI UKSW dan aplikasi pemumpang bus FTI UKSW. Pada aplikasi admin bus FTI UKSW tidak ada menu tampilan untuk login, sehingga tampilan awalnya setelah masuk ke aplikasi admin bus FTI UKSW dapat dilihat pada gambar 8.

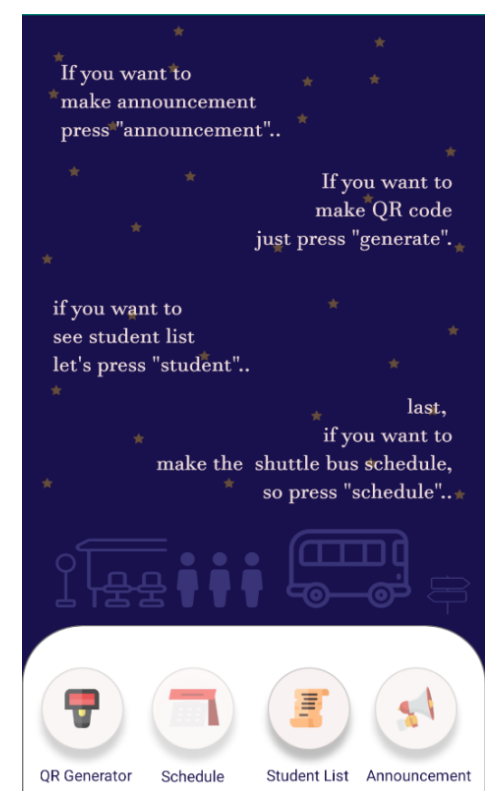

Gambar 8. Tampilan Awal Aplikasi Admin Bus FTI UKSW 
Pada Gambar 8 di tampilan awal aplikasi admin bus FTI UKSW terdapat penjelasan, dan beberapa menu lainnya yang tersedia. Menu tersebut adalah menu $Q R$ Generator, Schedule, Student List, dan Announcement. Menu $Q R$ Generator berfungsi untuk membuat $Q R$ Barcode untuk nantinya dapat digunakan oleh penumpang saat melakukan scan barcode. Berikut adalah tampilan menu QR Generator yang terdapat pada gambar 9.

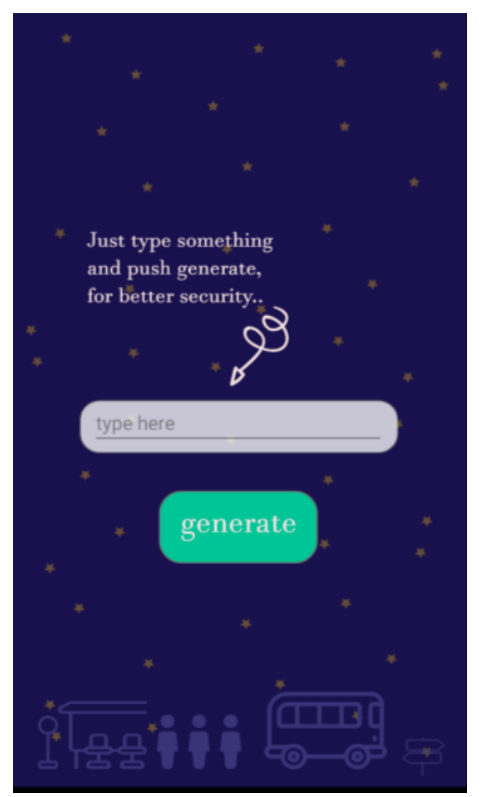

\section{Gambar 9. Tampilan Menu QR Generator Aplikasi Admin Bus FTI UKSW}

Pada Gambar 9 terdapat perintah untuk mengetik sesuatu pada kolom yang sudah disediakan dan nantinya akan digunakan sebagai syarat untuk melakukan generate $Q R$ Barcode. Setelah berhasil di generate, maka akan keluar tampilan $Q R$ Barcode hasil generate tersebut. Selanjutnya selain menu $Q R$ generator, ada juga menu schedule. Menu schedule adalah menu yang memiliki fungsi untuk mengatur pemberitahuan jadwal keberangkatan bus FTI UKSW. Tampilan menu schedule dapat dilihat pada gambar 10.

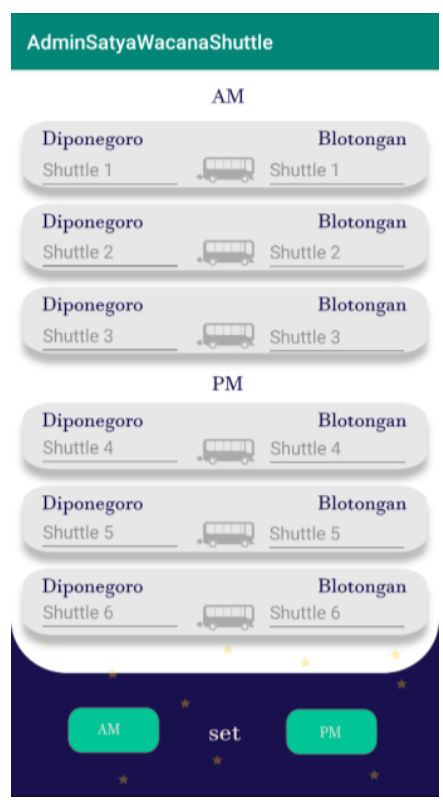

\section{Gambar 10. Tampilan Menu Schedule Aplikasi Admin Bus FTI UKSW}

Pada gambar 10 diperlihatkan ada beberapa kolom yang telah tersedia untuk mengatur jadwal keberangkatan bus tersebut. Nantinya jika sudah selesai mengatur jadwal keberangkatan bus, maka nantinya sistem akan melemparkan perintah untuk menyimpan pengaturan jadwal keberangkatan bus tadi didalam database, yang kemudian nantinya penumpang dapat melihat pemberitahuan jadwal bus yg sudah disimpan pada database tersebut di dalam aplikasi penumpang bus FTI UKSW. 
Kemudian menu student list adalah menu yang memiliki fungsi untuk melihat data mahasiswa. Data mahasiswa yang dimaksud seperti, nim mahasiswa, nama mahasiswa, nomor handphone. Selanjutnya yang terakhir adalah menu announcement. Menu announcement memiliki fungsi untuk melakukan update pengumuman seputar info bus, yang mungkin ada info bus terbaru yang ingin diberitahukan kepada penumpang bus tersebut. Tampilan menu announcement dapat dilihat pada gambar 11 .

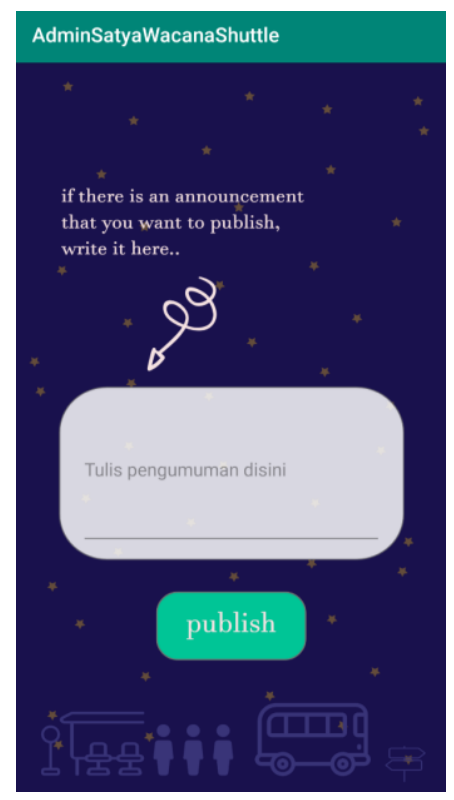

\section{Gambar 11. Tampilan Menu Announcement Aplikasi Bus FTI UKSW}

Pada Gambar 11 menu announcement telah disediakan kolom untuk tempat menulis atau mengetik pengumuman atau informasi terbaru seputar bus. Nantinya jika pengumuman tersebut sudah di publish maka sistem akan menyimpan pengumuman baru tersebut di dalam database, dan penumpang bus nantinya dapat melihat announcement atau pengumuman terbaru tersebut dari aplikasi penumpang bus FTI UKSW. Kemudian pada tampilan aplikasi penumpang bus FTI UKSW memiliki tampilan yang berbeda dengan aplikasi admin bus FTI UKSW. Di dalam aplikasi penumpang bus FTI UKSW, penumpang wajib login terlebih dahulu sebelum masuk ke tampilan menu utama pada aplikasi tersebut.Tampilan login aplikasi penumpang bus FTI UKSW dapat dilihat pada gambar 12 .

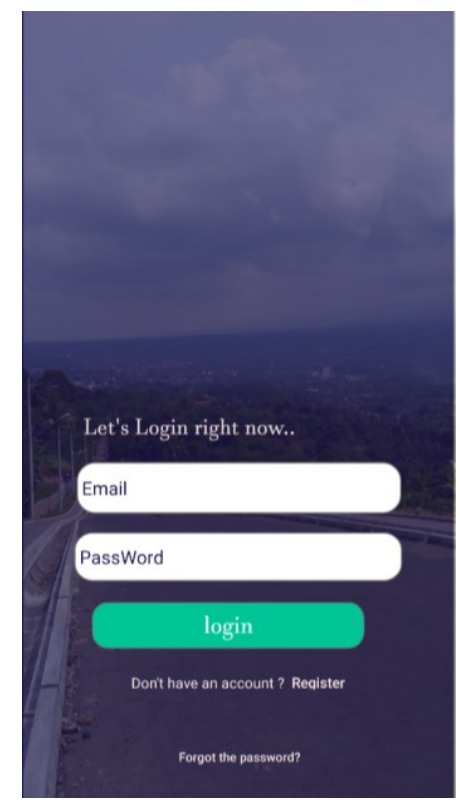

Gambar 12 Tampilan Login Aplikasi Penumpang Bus FTI UKSW

Pada gambar 12 tampilan login terdapat kolom isian email dan password yang harus diisi untuk dapat login ke dalam menu aplikasi penumpang bus FTI UKSW. Jika sudah berhasil login maka nantinya penumpang akan 
dibawa diarahkan masuk ke tampilan menu utama pada aplikasi penumpang bus FTI UKSW. Tampilan menu utama aplikasi penumpang bus FTI UKSW dapat dilihat pada gambar 13.

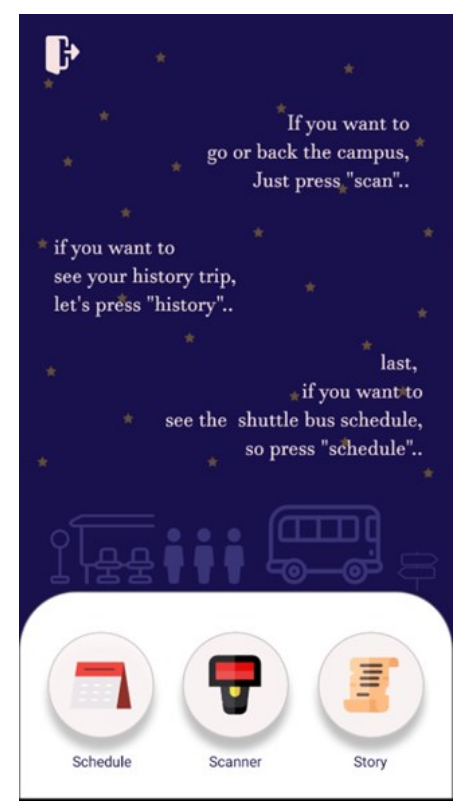

\section{Gambar 13. Tampilan Menu Utama Aplikasi Penumpang Bus FTI UKSW}

Pada gambar 13 terdapat penjelasan tentang fungsi menu, tombol logout akun yang terdapat di pojok kiri atas dan juga terdapat 3 menu yang ada di dalam menu utama aplikasi penumpang bus FTI UKSW tersebut. 3 menu tersebut adalah menu schedule, scanner, story. Selain Menu schedule di dalam aplikasi penumpang bus FTI UKSW memiliki fungsi untuk melihat jadwal bus dan pengumuman. Tampilan menu schedule dapat dilihat pada gambar 14.

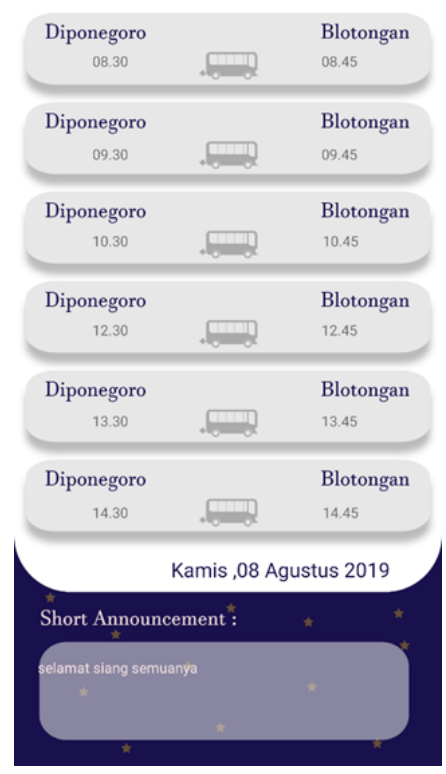

\section{Gambar 14. Tampilan Menu Schedule Aplikasi Penumpang Bus FTI UKSW}

Pada gambar 14, penumpang bus dapat melihat jadwal bus dan pengumuman atau informasi terbaru yang sudah tersimpan di database, yang dimana sebelumnya sudah di publikasi oleh admin. Selain menu schedule, yang kedua adalah menu scanner. Menu scanner adalah menu yang memiliki fungsi untuk melakukan scan barcode pada barcode yang sebelumnya sudah disediakan atau di generate oleh admin. Jika penumpang telah berhasil melakukan scan barcode maka akan muncul tampilan nama penumpang,nim mahasiswa serta waktu kejadian saat melakukan scan barcode tadi. Tampilan hasil scan barcode tersebut dapat dilihat pada gambar 15 . 


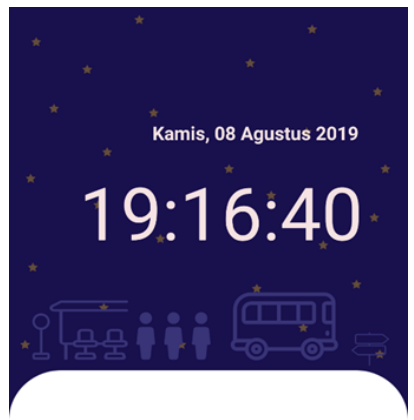

\section{3}

Daniel

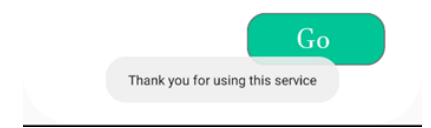

\section{Gambar 15. Tampilan Hasil Scan Barcode Pada Aplikasi Penumpang Bus FTI UKSW}

Pada gambar 15 dapat dilihat bahwa setelah berhasil melakukan scan barcode, maka penumpang bus akan mendapat tampilan informasi seperti waktu kejadian saat melakukan scan barcode tadi, nim mahasiswa penumpang, nama penumpang, serta terdapat tombol go dibagian paling bawah. Kemudian penumpang bus perlu menekan pada tombol go agar hasil scan barcode tersebut dapat dikirimkan oleh sistem untuk dapat disimpan ke database. Sehingga nantinya informasi hasil scan barcode tersebut dapat dilihat oleh penumpang bus kembali pada menu story yang diambil dari penyimpanan hasil scan barcode sebelumnya tadi yang sudah tersimpan di dalam database tersebut. Selanjutnya menu terakhir yang terdapat di dalam aplikasi penumpang bus FTI UKSW adalah menu story. Menu story adalah menu yang memiliki fungsi untuk melihat kembali hasil scan barcode yang dimana penumpang bus sebelumnya sudah berhasil melakukan scan barcode tersebut. Tampilan menu story pada aplikasi penumpang bus FTI UKSW dapat dilihat pada gambar 16.

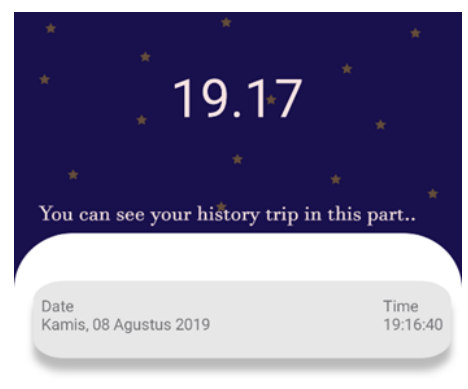

\section{Gambar 16. Tampilan Menu Story Pada Aplikasi Penumpang Bus FTI UKSW}

Pada Gambar 16 menampilkan waktu secara realtime saat penumpang bus mengakses menu story. Dan di bawahnya, juga terdapat informasi hasil scan barcode yang sebelumnya sudah dilakukan oleh penumpang bus. Proses scan barcode yang terdapat di aplikasi penumpang bus FTI UKSW dibuat menggunakan android studio dan terdapat 2 kode program untuk membentuk proses scan barcode pada sistem aplikasi tersebut. Berikut adalah 2 kode program untuk membentuk proses scan barcode pada sistem aplikasi bus FTI UKSW.

\section{Kode Program 1}

$\cdots$

1. COverride

2. protected void oncreate (Bundle savedInstancestate) \{

3. super.oncreate (savedInstancestate);

4. mScannerView = new ZXingScannerView (this);

5. setContentView (mScannerView);

6.

7. databaseReference = FirebaseDatabase.getInstance().getReference();

8. text $=$ getIntent ().getstringExtra ("text");

9.

10. date $=$ new Date ();

11. $\operatorname{sdf}=$ new SimpleDateFormat ("ddMMMMyyyy"); 
12. txtTanggal = sdf. format (date);

..

Pada kode program 1 adalah coding dari fungsi proses scan barcode, yang dimana pada coding tersebut terdapat kata ZXingScannerView yang digunakan untuk membaca barcode. Diproses ini juga di ambil waktu nya untuk nanti disimpan dan untuk ditampilkan kembali setelah scan barcode tersebut berhasil.

\section{Kode Program 2}

...

1. Override

2. public void onResume() \{

3. super.onResume ();

4. mScannerView. setResultHandler(this);

5. mScannerView.startCamera();

6. $\}$

7.

8. @override

9. public void onPause() \{

10. super.onPause();

11. mScannerView.stopCamera();

12. $\}$

. .

Kode program 2 menunjukkan proses pengaturan kamera agar dapat digunakan saat akan melakukan scan barcode. Pada baris 1 sampai ke baris 6 menunjukkan fungsi kamera agar dapat memulai proses menangkap gambar barcode. Dan pada baris 8 sampai ke baris 12 menunjukkan fungsi kamera agar dapat berhenti melakukan penangkapan gambar setelah gambar barcode tersebut berhasil ditangkap.

Pengujian aplikasi dilakukan dengan melakukan pengujian pada fungsi sistem aplikasi yang telah dibuat, untuk menemukan atau mencari kesalahan/bug agar aplikasi dapat berjalan dengan baik dan sesuai dengan kebutuhan pengguna/user. Pengujian sistem aplikasi bus FTI UKSW menggunakan dua teknik pengujian yaitu pengujian alpha dan pengujian beta. Pengujian beta adalah adalah pengujian yang dilakukan oleh pengguna/user terhadap aplikasi tersebut. Pengujian beta disini menggunakan kuesioner yang berisi pertanyaan-pertanyaan seputar aplikasi bus FTI UKSW yang telah diedarkan ke beberapa mahasiswa atau penumpang bus FTI UKSW. Hasil kuesioner tentang aplikasi bus FTI UKSW dapat dilihat pada Tabel 1.

\subsection{Kuesioner}

Tabel 1. Hasil Kuesioner Aplikasi Bus FTI UKSW

\begin{tabular}{|c|c|c|c|c|c|c|}
\hline No & Pertanyaan & STS & $T S$ & $C S$ & $S$ & $S S$ \\
\hline 1 & Aplikasi bus FTI UKSW mudah untuk digunakan & 0 & 0 & 4 & 9 & 7 \\
\hline 2 & $\begin{array}{l}\text { Menu pada aplikasi bus FTI UKSW mudah } \\
\text { dipahami }\end{array}$ & 0 & 0 & 7 & 5 & 8 \\
\hline 3 & $\begin{array}{l}\text { Aplikasi bus FTI UKSW membantu mahasiswa atal } \\
\text { penumpang mendapatkan informasi seputar bus }\end{array}$ & 0 & 0 & 3 & 7 & 10 \\
\hline 4 & $\begin{array}{l}\text { Fitur scan barcode mempermudah mahasiswa } \\
\text { atau penumpang dalam melakukan absensi saat } \\
\text { menggunakan bus FTI UKSW }\end{array}$ & 0 & 0 & 1 & 8 & 11 \\
\hline
\end{tabular}

Setelah dibuat hasil data kuesioner seperti pada Tabel 1, maka selanjutnya adalah di lakukan perhitungan presentase pada jawaban setiap setiap pertanyaan di kuesioner tersebut. Adapun perhitungan yang dilakukan menggunakan skala Likert, yang dimana setiap masing-masing jawaban diberi skor 1-5 dengan penjelasan seperti berikut:

1) Sangat Tidak Setuju (STS) $=1$

2) Tidak Setuju (TS) $=2$

3) Cukup Setuju (CS) $=3$

4) $\quad$ Setuju $(S)=4$

5) Sangat Setuju (SS) $=5$

Berikut adalah hasil analisis data kuesioner kepada 20 mahasiswa atau penumpang bus FTI UKSW, hasil analisis data kuesioner pada pertanyaan 1 menunjukkan sebanyak 35\% mahasiswa menjawab sangat setuju, 45\% mahasiswa menjawab cukup setuju, 20\% mahasiswa menjawab cukup setuju. Sehingga dapat disimpulkan bahwa aplikasi bus FTI UKSW mudah untuk digunakan. Kemudian hasil analisis data kuesioner pada pertanyaan 2 menunjukkan sebanyak 40\% mahasiswa menjawab sangat setuju, 25\% mahasiswa menjawab cukup setuju, 
35\% mahasiswa menjawab cukup setuju. Sehingga dapat disimpulkan bahwa menu pada aplikasi bus FTI UKSW mudah untuk dipahami.

Hasil analisis data kuesioner pada pertanyaan 3 menunjukkan sebanyak 50\% mahasiswa menjawab sangat setuju, 35\% mahasiswa menjawab cukup setuju, 15\% mahasiswa menjawab cukup setuju. Sehingga dapat disimpulkan bahwa aplikasi bus FTI UKSW sangat membantu mahasiswa atau penumpang untuk mendapatkan info seputar bus. Hasil analisis data kuesioner pada pertanyaan 4 menunjukkan sebanyak 55\% mahasiswa menjawab sangat setuju, 40\% mahasiswa menjawab cukup setuju, 5\% mahasiswa menjawab cukup setuju. Sehingga dapat disimpulkan bahwa fitur scan barcode yang terdapat pada aplikasi sangat mempermudah mahasiswa atau penumpang dalam melakukan absensi saat menggunakan bus FTI UKSW.

\section{KESIMPULAN DAN SARAN}

Berdasarkan dari hasil pembahasan perancangan aplikasi bus FTI UKSW, telah berhasil membuat aplikasi bus FTI UKSW menggunakan barcode berbasis android, yang dimana sebelumnya belum tersedia aplikasi bus FTI UKSW tersebut. Berdasarkan hasil kuesioner aplikasi bus FTI UKSW didapatkan kesimpulan bahwa aplikasi bus FTI UKSW mudah dalam penggunaannya, aplikasi bus, menu pada aplikasi bus FTI UKSW mudah dipahami, fitur scan barcode mempermudah mahasiswa atau penumpang bus dalam melakukan absensi saat menggunakan bus FTI UKSW. Sehingga dari adanya fitur scan barcode tersebut, diharapkan agar aplikasi bus FTI UKSW ini kedepannya dapat lebih lagi membantu pihak universitas agar dapat mendata mahasiswa atau penumpang bus yang menggunakan bus FTI UKSW. Hal positif secara detail lainnya dari dibuatnya aplikasi bus FTI UKSW ini adalah dapat membantu mahasiswa untuk mengetahui informasi jadwal bus serta pengumuman seputar bus terbaru secara realtime atau sesuai dengan waktu kejadian yang sebenarnya. Saran untuk pengembangan aplikasi ini selanjutnya adalah diperlukan penambahan fitur atau menu lagi di dalam aplikasi bus FTI UKSW, sehingga nantinya dapat lebih membantu lebih lagi baik itu bagi mahasiswa atau penumpang bus dan juga bagi pihak universitas nanti untuk kedepannya lagi.

\section{DAFTAR PUSTAKA}

[1] Ambika, Y.P.W. (2017). Perancangan dan Implementasi Aplikasi Monitoring Pekerjaan Karyawan PT Pura Barutama Unit Engineering dengan Library Google Mobile Vision berbasis Android. Salatiga: Jurusan Teknik Informatika Universitas Kristen Satya Wacana Salatiga.

[2] Hakiky, Fifin. (2011). Pengukuran Kinerja Goodreads Application Programming Interface (API) Pada Aplikasi Mobile Android (Studi Kasus Untuk Pencarian Data Buku). Bandung: Jurusan Teknik Informatika Institut Teknologi Nasional Bandung.

[3] Hanafi, Muhammad. (2017). Konsep Penelitian R\&D Dalam Bidang Pendidikan. Banten: UIN Sultan Maulana Hassanuddin Banten.

[4] Hasan, Fuad. (2015). Pemanfaatan QR Code Scanner Untuk Aplikasi Penampil Data Koleksi Pamer Di Museum Negeri Sonobudoyo Berbasis Android. Yogyakarta : Jurusan Teknik Informatika Universitas Islam Negeri Sunan kalijaga Yogyakarta.

[5] Jauhari, M.R. dan Subaeki, Beki. (2016). Aplikasi Info Halal Menggunakan Barcode Scanner Untuk Smartphone Android. Bandung: Jurusan Teknik Informatika Universitas Islam Negeri Sunan Gunung Djati Bandung.

[6] Prayoga, Hendra. (2015). Sistem Informasi Penjualan Berbasis Android Dengan Memanfaatkan QR-Code Dan Barcode. Malang: Jurusan Teknik Informatika Universitas Muhammadiyah Malang.

[7] Rahmelina, Liranti. (2017). Perancangan Mobile Learning Berbasis Android Pada Mata Kuliah Sistem Operasi Di STMIK Indonesia Padang. Padang: Jurusan Sistem Informasi Sekolah Tinggi Manajemen Informatika dan Komputer Indonesia Padang.

[8] Sikumbang, Alexsandri. (2015). E-Tiket Bus Trans Batam Dengan Menggunakan QR - Code System Berbasis Android. Batam: Jurusan Teknik Informatika Sekolah Tinggi Teknik Ibnu Sina.

[9] Sudarma, Made., Swamardika, I.B.A. (2017). Perancangan Aplikasi Sistem Informasi Medis Menggunakan Barcode Berbasis Desktop Dan Android. Bali : Jurusan Teknik Elektro dan Komputer Universitas Udayana Bali. 